\title{
Primary traumatic patellar dislocation
}

\author{
Chun-Hao Tsai ${ }^{1}$, Chin-Jung Hsu', Chih-Hung Hung ${ }^{1}$ and Horng-Chaung Hsu ${ }^{1,2^{*}}$
}

\begin{abstract}
Acute traumatic patellar dislocation is a common injury in the active and young adult populations. MRI of the knee is recommended in all patients who present with acute patellar dislocation. Numerous operative and non-operative methods have been described to treat the injuries; however, the ideal management of the acute traumatic patellar dislocation in young adults is still in debate. This article is intended to review the studies to the subjects of epidemiology, initial examination and management.
\end{abstract}

Keywords: Patella, Trauma, Dislocation, Medial patellofemoral ligament

\section{Introduction}

Acute traumatic patellar dislocation is the second most common cause of traumatic hemarthrosis of the knee and it accounts for approximately $3 \%$ of all knee injuries [1,2].

It is typically resulted from a sports injury and occurs about $2 / 3$ of the time in young, active patients under the age of 20. Most patellar dislocations are associated with participation in sports and physical activity [3-5]. The long-term impact of patellar dislocation and the resulting patellar instability can lead to considerable pain, recurrence, and even patellofemoral osteoarthritis [6].

\section{Definition}

The differentiation of acute primary patellar dislocation from habitual dislocation is important because the recommendations with varying treatment approaches were framed in the literatures. Primary (first-time) patellar dislocation is defined as a clinical entity that usually causes a traumatic disruption of the previously uninjured medial peripatellar structures $[3,7,8]$.

One of the common findings related to acute, primary, traumatic patellar dislocations is hemarthrosis of the knee, caused by rupture of the medial restraints of the patella.

\section{Incidence and risk factors}

The incidence rates of primary patellar dislocation in a population-based setting among adults were revealed in

\footnotetext{
* Correspondence: d4749@mail.cmuh.org.tw

'Department of Orthopaedic Surgery, China Medical University Hospital, School of Medicine, China Medical University, Taichung, Taiwan

${ }^{2}$ Department of Orthopaedic Surgery, China Medical University Hospital, No. 2, Yuh-Der Road, Taichung 404, Taiwan, Republic of China
}

some reports [3-5,9]. The average annual incidence for patellar dislocation injuries ranged between 5.8 and 7.0 per 100,000 person-years in the civilian population, and up to 29 per 100,000 person-years in the $10-17$ year age group. However, the incidence was increased to 69 per 100,000 person-years in the military population who needed to pass physical fitness tests and training requirements of military service [9]. Women were more likely to sustain a patellar dislocation injury than men. The trend of the highest rates for patellar dislocation injuries in the youngest age group, and rates declined with increasing age were observed not only in military but also in the civilian population-based studies [3-5,9]. Those previous findings may be associated with increased activity levels in younger individuals and predisposed to anatomic features rendering some youth more vulnerable.

\section{Injury mechanism}

Knee flexion and valgus have been noted as the leading mechanism of injury associated with patellar dislocation, accounting for as many as $93 \%$ of all cases [5]. Sillanpaa and colleagues reported that hemarthrosis, medial patellofemoral ligament injury, and medial retinacular disruption were presented in nearly all patients with acute traumatic primary patellar dislocation. Osteochondral fractures have been noted in nearly $25 \%$ of acute patellar dislocations [5].

Results obtained after patellar dislocation were reported from studies evaluating treatment approaches [10-14], but often no distinction was made between acute traumatic and recurrent instability. The risk 
factors could not be adequately determined due to lack of consistent and qualified reports in many articles. The trend of dislocation and recurrent instability was up to $80 \%$ of cases and attributable to predisposing factors of vastus medialis muscle hypoplasia, hyperlaxity of the ligaments $[15,16]$, increased femoral anteversion with compensatory external tibial torsion[17], trochlear dysplasia $[18,19]$, patella alta $[20,21]$, dysplastic patella, and increased Q-angle with lateralized tibial tuberosity and genu valgum $[22,23]$.

\section{Examination and diagnostic study}

The initial evaluation of a first-time traumatic patellar dislocation should include an appropriate patient history, family history of patellar dislocation and hyperlaxity, physical examination, and diagnostic studies. Sports (61\%) and dances (9\%) injuries are two common mechanisms of patellar dislocation. The risk of recurrence increased to 6-fold for patients with a history of contralateral patellar dislocation, which was as much as a previous dislocation event on the index knee [4].

Diagnostic and therapeutic aspiration of the knee joint should be performed in patients with moderate to severe effusions. Joint aspiration performed with/without a local anesthetic can relieve joint depression to achieve patient comfort and improve clinical examination and radiographic assessment (such as $45^{\circ}$ flexion Merchant view, $45^{\circ}$ flexion weight-bearing view, and $30^{\circ}$ lateral view, which are difficult to obtain in patients with an acute hemarthrosis). In addition, the presence of fatty globules may be indicative of an osteochondral fracture. In the acute setting, physical examination is important in making the diagnosis of acute lateral patellar dislocation and for noting any concurrent knee or lower extremity injury [24]. Assessment for malalignment of lower extremities and hypermobility of the contralateral knee are also suggested to be included [25].

Patellar apprehension and mobility should be assessed by medial and lateral patellar translation. Palpation is important in detecting areas of retinacular tenderness and soft tissue injury. Palpable defects in the vastus medialis obliquus (VMO), adductor mechanism, medial patellofemoral ligament (MPFL), and a grossly dislocatable patella are prognostic factors that may predict poor nonoperative outcomes [24].

Radiographic examination should include an AP extended knee weight-bearing view, a Mercer-Merchant view ( $45^{\circ}$ flexion weight-bearing view), and a $30^{\circ}$ flexion lateral view. A Merchant view in a "first-time" traumatic patellar dislocator shows an osteochondral fracture of the medial facet of the patella in a well-aligned patellofemoral joint with no lateral subluxation of the patella (Figure 1). Osteochondral fractures at the medal inferior edge of the patella are highly suggestive of injury

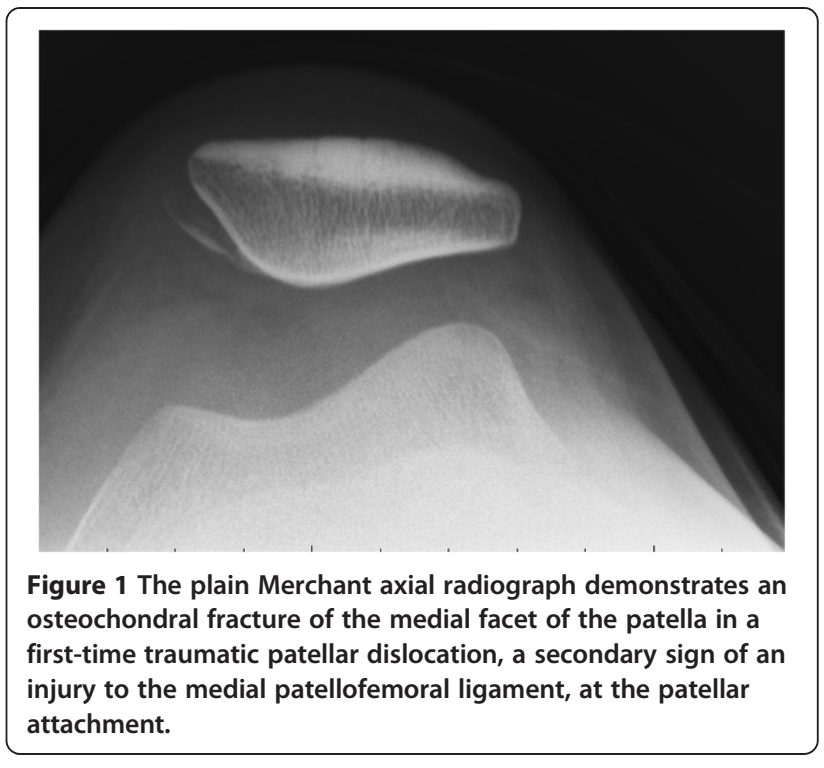

pattern. However, it has been reported to be missed in $30 \%$ to $40 \%$ of initial radiographs in both surgical and MRI studies [26,27].

CT scan could be used to evaluate the bony predisposing risk factors for dislocation, including patellofemoral alignment, the presence of osteochondral defects, patellar tilt, translation, tibial tuberosity trochlear groove distance, and trochlear dysplasia [28]. It is also helpful in evaluating long bone torsional deformities and determining the rotational relationship between the tibial tuberosity and femoral sulcus in varying degrees of knee flexion [24]. The cartilaginous femoral sulcus contour is shallower than the underlying bony sulcus in patients younger than 18 years old. Therefore, measurement of the bony femoral sulcus angle on radiograph or CT scan is less important than that of the cartilaginous femoral sulcus angle using ultrasound or MRI [29]. CT scan is also limited in looking at the location and extent of soft tissue defects of the medial patellar stabilizers.

Characteristic MRI findings of patellar dislocation include joint effusion, bruising of the medial patellar facet and lateral femoral condyle, osteochondral injury to the medial patella and anterolateral portion of the lateral femoral condyle. A concave impaction deformity of the inferomedial patella is a specific sign of lateral patellar dislocation $[7,30]$. But there is no correlation can be defined between initial size and size reduction in bone bruise volumetric and the presence/absence or type of associated injuries [31,32].

With the information available on utilizing newer types of magnetic resonance sequencing, MRI is becoming more specific in assisting the surgeon in deciding on nonoperative versus operative management to define the specific injured structure for surgical repair. MRI 
assessment is important to evaluate not only the chondral surfaces of the patellofemoral joint but also at the location an extent of soft tissue damage to the medial patellar stabilizers (including medial retinaculum , medial patellofemoral ligament and the vastus medialis obliquus) [33-35]. MRI with the most specificity in visualizing the medial patellofemoral ligament is the primary restraint to lateral subluxation of the patella in early flexion (Figure 2) [29,31].

\section{Treatment}

The squeals of a patient's first patellar dislocation can be harmful and have been well described in the literatures [36,37]. More than $50 \%$ of patients have complaints after the first-time dislocation of the patella [13], and will be likely to develop some level of osteoarthrosis of the patellofemoral joint after a long-term follow-up [38]. Moreover, recurrence rates after primary dislocation can be relatively high, up to $40 \%$ [39].

Proper treatment is essential in order to minimize squeals such as recurrent dislocation, painful subluxation, and osteoarthrosis. Whether initial stabilizing surgery for treatment of a primary traumatic patellar dislocation decreases the risk of further instability is still in debate. Results and recommendations on treatment of patellar dislocation vary widely and lack higher quality of evidence. The outcomes of conservative and operative management were compared in limited studies [10,40]. To our knowledge, there were only two prospective randomized trials regarding acute patellar dislocations had been published in the English-language literatures $[41,42]$. The redislocation rates were generally high, varying between $10 \%$ and $30 \%$ for surgical treatment $[1,14,23,40,43]$ and between $13 \%$ and $52 \%$ for conservative treatment $[10-13,40]$.
Arthroscopy should be performed if chondral injury or osteochondral fracture is suspected. Whenever the osteochondral fracture is greater than $10 \%$ of the patella articular surface or part of the weight-bearing portion of the lateral femoral condyle, it is recommended to perform open repair as long as the fragment is amendable to fixation.

Other than preferences for nonoperative treatment of primary patellar dislocations have been shown in previous studies $[41,44,45]$, patients with habitual dislocations and patellofemoral symptoms seem to be benefited from reconstructive surgery [46,47]. Stefancin and Parker recommended initial nonoperative treatment for first-time traumatic patellar dislocation in their systematic review of 70 articles, unless there are clinical, radiographic, CT, and/or MRI findings of chondral injury, osteochondral fractures, or large medial patellar stabilizer defects [2].

\section{Non-operative treatment}

There were few literatures addressing the nonoperative treatment of the primary patellar dislocation. But it is all agreed that patients should be immobilized initially for comfort (3-4 weeks) to allow immediate weight bearing as tolerated on crutches after close reduction of the lateral dislocated patella. Early mobilization is important in maintaining articular cartilage health [24]. Patellastabilizing braces were used as soon as comfort permitted, followed by beginning resisted close-chain exercises and passive range of motion in the brace [3]. The efficency of physical therapy after the first patellar dislocation; either the patellar braces or straps on the outcome, has not been reported in any study. There was still some debate for the best model of knee immobilizers. The effects were compared in patients treated with in a posterior splint, cylinder cast, or patellar bandage/brace
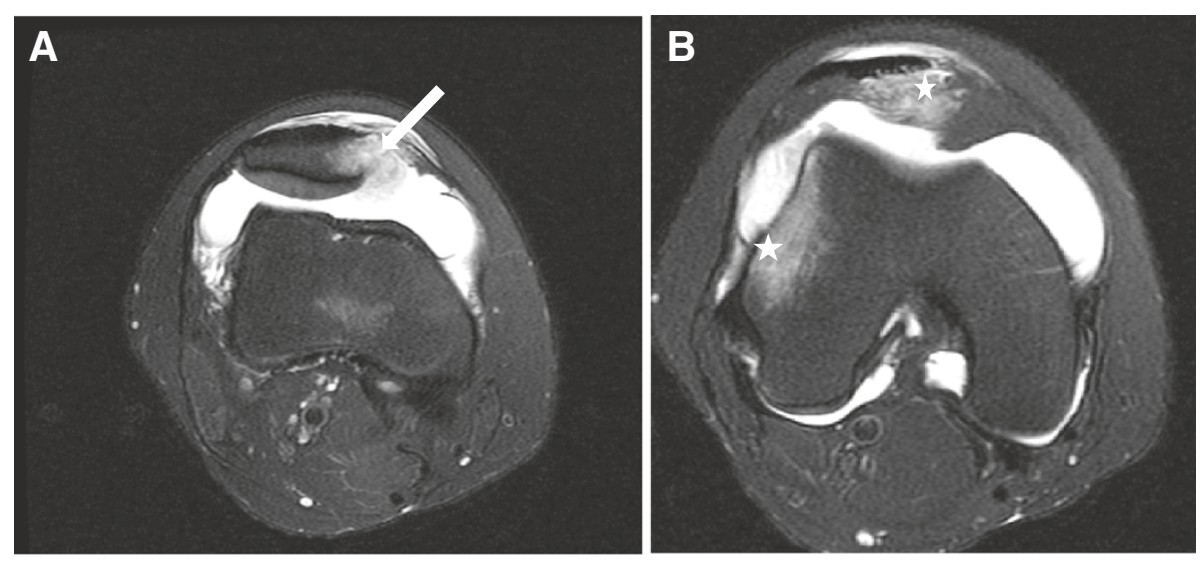

Figure 2 An axial T2-weighted fast-spin-echo magnetic resonance imaging scan illustrates a eighteen year-old female sustaining a primary traumatic lateral dislocation of the patella while jumping. Complete avulsion of the medial patellofemoral ligament from its femoral insertion can be seen (arrow) (Figure 2A). The bone contusions (stars) (Figure 2B) of the lateral femoral condyle and the medial patellar facet are noted. 
[13]. Results showed that the posterior splint group had the lowest proportion of knee joint restriction and lowest redislocation frequency per follow-up year. In the study using MRI to look at the effect of bracing on patella alignment and patellofemoral joint contact area in skeletally mature women with patellofemoral pain, the On-Track brace and the Patellar Tracking Orthosis (PTO) were shown to increase total patellofemoral joint contact area in comparison to the no-brace control group [48].

\section{Surgical treatment}

Surgical intervention for first-time traumatic patellar dislocation is indicated in the following situations: (1) evidence on imaging or clinical examination of osteochondral fracture or major chondral injury; (2) palpable or MRI findings of substantial disruption of the MPFLVMO-adductor mechanism; (3) a patella laterally subluxated on the plain Mercer-Merchant view with normal alignment on the contralateral knee; (4) a patient fails to improve with nonoperative management especially in the presence of one or more predisposing factors to patellar dislocation; and 5) subsequent redislocation [2]. Surgical stabilization significantly reduced the redislocation rate of primary traumatic patellar dislocation in a young adult population than those without surgical treatment, which was addressed in a prospective, randomized, controlled study [42].
There is high prevalence of medial patellofemoral ligament injury in association with acute patellar dislocation $[42,49,50]$. The injuries of the medial patellofemoral ligament and the medial retinaculum as well as hemarthrosis are the definite signs of an acute primary traumatic patellar dislocation[42]. It is reasonable and becomes more accepted to consider that large defects or avulsions are not going to heal or have a good functional outcome with closed treatment especially in individuals with high-level athletic participation and those with evidence of one or more predisposing factors. MPFL injury has been demonstrated as the primary constraint in preventing lateralization of the patella in studies [26,51]. Immediate surgical repair of the injured medial patellar stabilizers, including the vastus medialis obliqus muscle and the medial patellofemoral ligament is advocated in this situation. In our experience, the surgical repair of medial stabilizer with medical plication and arthroscopic removal of osteochondral fragment have satisfactory result and no recurrence of dislocation at least six months follow-up (Table 1).

\section{Conclusion}

Primary traumatic patellar dislocation is a common injury in young active population. The importance of detail initial evaluation with MRI cannot be underestimated. Recent studies have proved that initial surgical stabilization of the medial patellofemoral avulsion is beneficial in acute

Table 1 The table shows the patient data, image data and surgical detail in our institute within 2 years and no recurrence of dislocation at least six months follow-up

\begin{tabular}{|c|c|c|c|c|c|c|c|c|c|}
\hline \multirow[t]{2}{*}{ Age } & \multirow[t]{2}{*}{ Gender } & \multirow{2}{*}{$\begin{array}{l}\text { Injury } \\
\text { side }\end{array}$} & \multirow[t]{2}{*}{ Mechanism } & \multicolumn{2}{|c|}{ MRI finding } & \multicolumn{3}{|l|}{ Surgery } & \multirow{2}{*}{$\begin{array}{l}\text { Follow-up } \\
\text { (months) }\end{array}$} \\
\hline & & & & $\begin{array}{l}\text { Bone } \\
\text { contusion }\end{array}$ & MPFL tear & $\begin{array}{l}\text { Medial } \\
\text { plication }\end{array}$ & $\begin{array}{l}\text { Lateral } \\
\text { release }\end{array}$ & $\begin{array}{l}\text { Removal of } \\
\text { osteochondral } \\
\text { fragment }\end{array}$ & \\
\hline 15 & $\mathrm{~F}$ & Left & Fall & + & Femoral side & + & + & - & 20 \\
\hline 13 & M & Right & Run & + & Both & + & + & + & 15 \\
\hline 21 & M & Right & Non trauma & + & Patella side & + & + & - & 13 \\
\hline 18 & $\mathrm{~F}$ & Left & Tennis & + & Patella side & + & + & - & 12 \\
\hline 21 & $\mathrm{~F}$ & Right & Fall & + & Patella side & + & + & - & 12 \\
\hline 20 & $\mathrm{~F}$ & Left & Direct contusion & + & Patella side & + & + & - & 10 \\
\hline 31 & M & Left & Fall & + & Femoral side & + & + & + & 9 \\
\hline 23 & $\mathrm{~F}$ & Left & $M B C$ & + & Femoral side & + & + & & 9 \\
\hline 13 & $\mathrm{~F}$ & Left & Dance & + & Femoral side & + & + & + & 9 \\
\hline 19 & M & Left & $\mathrm{MBC}$ & + & Both & + & + & - & 8 \\
\hline 16 & M & Right & Basketball & + & Femoral side & + & + & + & 8 \\
\hline 16 & $\mathrm{~F}$ & Left & Fall & + & Patella side & + & + & - & 7 \\
\hline 31 & $\mathrm{~F}$ & Left & Fall & + & Patella side & + & + & - & 7 \\
\hline 16 & M & Left & Basketball & + & Both & + & + & + & 7 \\
\hline 22 & M & Right & Sprain & + & Patella side & + & + & + & 6 \\
\hline
\end{tabular}


primary traumatic patellar dislocation. Additional prospective randomized comparison studies with longer-term follow-up are needed to identify risk factors like behavioral factors, strength, neuromuscular control, and postural stability in high-risk populations for future research.

\section{Competing interests}

The authors declare that they have no competing interests.

\section{Authors' contributions}

$\mathrm{HHC}$ designed the main framework and also performed final check for this manuscript. TCH carried out the paper survey and drafted the manuscript and both $\mathrm{HCJ}$ and $\mathrm{HCH}$ edited the manuscript. All authors read and approved the final manuscript

Received: 12 April 2011 Accepted: 2 April 2012

Published: 6 June 2012

\section{References}

1. Harilainen A, Myllynen P, Antila H, Seitsalo S: The significance of arthroscopy and examination under anaesthesia in the diagnosis of fresh injury haemarthrosis of the knee joint. Injury 1988, 19:21-24.

2. Stefancin JJ, Parker RD: First-time traumatic patellar dislocation: a systematic review. Clin Orthop Relat Res 2007, 455:93-101.

3. Atkin DM, Fithian DC, Marangi KS, Stone ML, Dobson BE, Mendelsohn C: Characteristics of patients with primary acute lateral patellar dislocation and their recovery within the first 6 months of injury. Am J Sports Med 2000, 28:472-479.

4. Fithian DC, Paxton EW, Stone ML, Silva P, Davis DK, Elias DA, White LM: Epidemiology and natural history of acute patellar dislocation. Am J Sports Med 2004, 32:1114-1121.

5. Sillanpaa P, Mattila VM, livonen T, Visuri T, Pihlajamaki H: Incidence and risk factors of acute traumatic primary patellar dislocation. Med Sci Sports Exerc 2008, 40:606-611.

6. Riedel A, Hartig W, Seeger G, Gartner U, Brauer K, Arendt T: Principles of rat subcortical forebrain organization: a study using histological techniques and multiple fluorescence labeling. J Chem Neuroanat 2002, 23:75-104.

7. Virolainen $H$, Visuri T, Kuusela T: Acute dislocation of the patella: MR findings. Radiology 1993, 189:243-246.

8. Kirsch MD, Fitzgerald SW, Friedman H, Rogers LF: Transient lateral patellar dislocation: diagnosis with MR imaging. AJR Am J Roentgenol 1993, 161:109-113.

9. Hsiao M, Owens BD, Burks R, Sturdivant RX, Cameron KL: Incidence of acute traumatic patellar dislocation among active-duty United States military service members. Am J Sports Med 2010, 38:1997-2004.

10. Cash JD, Hughston JC: Treatment of acute patellar dislocation. Am J Sports Med 1988, 16:244-249.

11. Larsen $\mathrm{E}$, Lauridsen F: Conservative treatment of patellar dislocations. Influence of evident factors on the tendency to redislocation and the therapeutic result. Clin Orthop Relat Res 1982, 171:131-136.

12. Cofield RH, Bryan RS: Acute dislocation of the patella: results of conservative treatment. J Trauma 1977, 17:526-531.

13. Maenpaa H, Lehto MU: Patellar dislocation. The long-term results of nonoperative management in 100 patients. Am J Sports Med 1997, 25:213-217

14. Vainionpaa S, Laasonen E, Silvennoinen T, Vasenius J, Rokkanen P: Acute dislocation of the patella, A prospective review of operative treatment. J Bone Joint Surg Br 1990, 72:366-369.

15. Runow A: The dislocating patella, Etiology and prognosis in relation to generalized joint laxity and anatomy of the patellar articulation. Acta Orthop Scand Suppl 1983, 201:1-53.

16. Maenpaa H, Lehto MU: Patellar dislocation has predisposing factors, A roentgenographic study on lateral and tangential views in patients and healthy controls. Knee Surg Sports Traumatol Arthrosc 1996, 4:212-216.

17. Elgafy $\mathrm{H}, \mathrm{El}-$ Kawy $\mathrm{S}$, Elsafy M, Ebraheim NA: Internal torsion of the distal femur as a cause of habitual dislocation of the patella: a case report and a review of causes of patellar dislocation. Am J Orthop (Belle Mead NJ) 2005, 34:246-248.
18. Malghem J, Maldague B: Depth insufficiency of the proximal trochlear groove on lateral radiographs of the knee: relation to patellar dislocation. Radiology 1989, 170:507-510.

19. Dejour H, Walch G, Nove-Josserand L, Guier C: Factors of patellar instability: an anatomic radiographic study. Knee Surg Sports Traumatol Arthrosc 1994, 2:19-26

20. Insall J, Goldberg V, Salvati E: Recurrent dislocation and the high-riding patella. Clin Orthop Relat Res 1972, 88:67-69.

21. Blackburne JS, Peel TE: A new method of measuring patellar height. J Bone Joint Surg Br 1977, 59:241-242.

22. Rorabeck CH, Bobechko WP: Acute dislocation of the patella with osteochondral fracture: a review of eighteen cases. J Bone Joint Surg Br 1976, 58:237-240.

23. Hawkins RJ, Bell RH, Anisette G: Acute patellar dislocations. The natural history. Am J Sports Med 1986, 14:117-120.

24. Hinton RY, Sharma KM: Acute and recurrent patellar instability in the young athlete. Orthop Clin North Am 2003, 34:385-396.

25. Stanitski CL: Articular hypermobility and chondral injury in patients with acute patellar dislocation. Am J Sports Med 1995, 23:146-150.

26. Desio SM, Burks RT, Bachus KN: Soft tissue restraints to lateral patellar translation in the human knee. Am J Sports Med 1998, 26:59-65.

27. Stanitski CL, Paletta GA Jr: 1998. Am J Sports Med 1998, 26:52-55.

28. Hing CB, Shepstone L, Marshall T, Donell ST: A laterally positioned concave trochlear groove prevents patellar dislocation. Clin Orthop Relat Res 2006 447:187-194.

29. Nietosvaara $Y$, Aalto $K$ : The cartilaginous femoral sulcus in children with patellar dislocation: an ultrasonographic study. J Pediatr Orthop 1997, 17:50-53.

30. Elias DA, White LM, Fithian DC: Acute lateral patellar dislocation at MR imaging: injury patterns of medial patellar soft-tissue restraints and osteochondral injuries of the inferomedial patella. Radiology 2002, 225:736-743.

31. Davies NH, Niall D, King LJ, Lavelle J, Healy JC: Magnetic resonance imaging of bone bruising in the acutely injured knee-short-term outcome. Clin Radiol 2004, 59:439-445.

32. Paakkala A, Sillanpaa P, Huhtala H, Paakkala T, Maenpaa H: Bone bruise in acute traumatic patellar dislocation: volumetric magnetic resonance imaging analysis with follow-up mean of 12 months. Skeletal Radiol 2010, 39:675-682.

33. Nomura $E$, Horiuchi $Y$, Inoue M: Correlation of MR imaging findings and open exploration of medial patellofemoral ligament injuries in acute patellar dislocations. Knee 2002, 9:139-143.

34. Sanders TG, Morrison WB, Singleton BA, Miller MD, Cornum KG: Medial patellofemoral ligament injury following acute transient dislocation of the patella: MR findings with surgical correlation in 14 patients. J Comput Assist Tomogr 2001, 25:957-962.

35. Spritzer CE, Courneya DL, Burk DL Jr, Garrett WE, Strong JA: Medial retinacular complex injury in acute patellar dislocation: MR findings and surgical implications. AJR Am J Roentgenol 1997, 168:117-122.

36. Arnbjornsson A, Egund N, Rydling O, Stockerup R, Ryd L: The natural history of recurrent dislocation of the patella, Long-term results of conservative and operative treatment. J Bone Joint Surg Br 1992, 74:140-142.

37. Maenpaa $\mathrm{H}$ : The dislocating patella. Predisposing factors and a clinical, radiological and functional follow-up study of patients treated primarily nonoperatively. Ann Chir Gynaecol 1998, 87:248-249.

38. Maenpaa $\mathrm{H}$, Lehto MU: Patellofemoral osteoarthritis after patellar dislocation. Clin Orthop Relat Res 1997, 339:156-162.

39. Maenpaa H, Huhtala H, Lehto MU: Recurrence after patellar dislocation. Redislocation in 37/75 patients followed for 6-24 years. Acta Orthop Scand 1997, 68:424-426.

40. Nikku R, Nietosvaara Y, Kallio PE, Aalto K, Michelsson JE: Operative versus closed treatment of primary dislocation of the patella. Similar 2-year results in 125 randomized patients. Acta Orthop Scand 1997, 68:419-423.

41. Nikku R, Nietosvaara Y, Aalto K, Kallio PE: Operative treatment of primary patellar dislocation does not improve medium-term outcome: A 7-year follow-up report and risk analysis of 127 randomized patients. Acta Orthop 2005, 76:699-704.

42. Sillanpaa PJ, Mattila VM, Maenpaa H, Kiuru M, Visuri T, Pihlajamaki H: Treatment with and without initial stabilizing surgery for primary traumatic patellar dislocation. A prospective randomized study. I Bone Joint Surg Am 2009, 91:263-273. 
43. Harilainen A, Sandelin J: Prospective long-term results of operative treatment in primary dislocation of the patella. Knee Surg Sports Traumatol Arthrosc 1993, 1:100-103.

44. Arendt EA, Fithian DC, Cohen E: Current concepts of lateral patella dislocation. Clin Sports Med 2002, 21:499-519.

45. Buchner M, Baudendistel B, Sabo D, Schmitt H: Acute traumatic primary patellar dislocation: long-term results comparing conservative and surgical treatment. Clin J Sport Med 2005, 15:62-66.

46. Fithian DC, Paxton EW, Cohen AB: Indications in the treatment of patellar instability. J Knee Surg 2004, 17:47-56.

47. Koskinen SK, Rantanen JP, Nelimarkka OI, Kujala UM: Effect of Elmslie-Trillat and Roux-Goldthwait procedures on patellofemoral relationships and symptoms in patients with patellar dislocations. Am J Knee Surg 1998, 11:167-173.

48. Powers CM, Ward SR, Chan LD, Chen YJ, Terk MR: The effect of bracing on patella alignment and patellofemoral joint contact area. Med Sci Sports Exerc 2004, 36:1226-1232.

49. Garth WP Jr, DiChristina DG, Holt G: Delayed proximal repair and distal realignment after patellar dislocation. Clin Orthop Relat Res 2000, 377:132-144.

50. Ahmad CS, Stein BE, Matuz D, Henry JH: Immediate surgical repair of the medial patellar stabilizers for acute patellar dislocation. A review of eight cases. Am J Sports Med 2000, 28:804-810.

51. Hautamaa PV, Fithian DC, Kaufman KR, Daniel DM, Pohlmeyer AM: Medial soft tissue restraints in lateral patellar instability and repair. Clin Orthop Relat Res 1998, 349:174-182.

\section{Submit your next manuscript to BioMed Central and take full advantage of:}

- Convenient online submission

- Thorough peer review

- No space constraints or color figure charges

- Immediate publication on acceptance

- Inclusion in PubMed, CAS, Scopus and Google Scholar

- Research which is freely available for redistribution 